doctor's awareness about current drug treatment, and is in the overall interests of patient care.

We thank all doctors in ward 4, Aberdeen Royal Infirmary, and ward 3 Woodend General Hospital, who participated in this study and gave helpful advice. We also acknowledge the financial support of the DHSS and SHHD to the Medicines Evaluation and Monitoring Group.

${ }^{1}$ Crooks, J, et al, Lancet, 1965, 1, 373.

${ }^{2}$ Beveridge, T, and Petrie, J C, British Medical fournal, 1972, 2, 37.

(Accepted 3 October 1978)

Medicines Evaluation and Monitoring Group, Department of

Community Medicine, University of Aberdeen

Z G ERSKINE, $\mathrm{MB}, \mathrm{CHB}$, research fellow

D C MOIR, MD, MFCM, lecturer

Department of Therapeutics and Clinical Pharmacology, University of Aberdeen

T A JEFFERS, MRCP, clinical senior lecturer
J C PETRIE, MRCP, senior lecture

The incidence in this series of Nigerians of $30 \%$ is similar to the incidences in the South African and Western series. The finding that patients who had undergone prostatectomy had the highest incidence of DVT $(72 \%)$ also agrees with findings in other studies. The Nigerian patient aged 40 and over is therefore probably at similar risk of developing DVT as the Caucasian.

I thank the Research Committee of the College of Medical Sciences, University of Benin, Benin City, Nigeria, for providing funds for this study and Miss Queen Okwuashi for secretarial help.

This paper was read at the 3rd Scientific Conference of the Nigerian Surgical Research Society held in the University of Lagos in November 1977.

${ }^{1}$ Burkitt, D P, British Medical fournal, 1972, 2, 556.

Osime, U, Lawrie, J, and Lawrie, H, Nigerian Medical fournal, 1976, 6, 26.

${ }^{3}$ Flanc, C, Kakkar, V V, and Clarke, M B, British Fournal of Surgery, 1968, 55, 742.

${ }^{4}$ Hassan, M A, Rahman, E A, and Rahman, I A, British fournal of Surgery, 1974, 61, 650 .

${ }^{5}$ Joffe, S N, British Fournal of Surgery, 1974, 61, 982.

(Accepted 3 October 1978)

Department of Surgery, University of Benin Traching Hospital, Benin City, Nigeria

U OSIME, FRCS, FMCS(NIG), consultant surgeon

\section{Incidence of postoperative deep vein thrombosis in Nigerians using ${ }^{125}$ I-labelled fibrinogen}

The incidence of clinically detected postoperative deep vein thrombosis (DVT) in Africans has been reported to be low, ${ }^{12}$ while studies in Western series have shown a high incidence using ${ }^{125}$ I-labelled fibrinogen. There have been few studies of the incidence of DVT in Africans using ${ }^{125} \mathrm{I}$-fibrinogen, and this report describes the true incidence, as detected by ${ }^{125} \mathrm{I}$-fibrinogen, among Nigerians.

\section{Patients, methods, and results}

One-hundred and twelve consecutive Nigerian patients (92 men, 20 women) aged 40-94 years (mean 62 years) undergoing surgery under general anaesthesia in the University of Benin Teaching Hospital were studied. Ninety per cent of the patients were from the urban area of Benin city, comprising civil servants, factory workers, and labourers, while the remaining $10 \%$ came from the rural areas of Bendel State and were mostly farmers. The diet of both groups was essentially a high-fibre Nigerian one. The weights of some of the patients were not recorded but most were of average weight. Patients who had operations on the neck and legs or had a recent history of DVT were excluded. The thyroid gland was blocked by giving sodium iodide $100 \mathrm{mg}$ orally 24 hours before operation and then once a day for three weeks; $100 \mu \mathrm{Ci}$ of ${ }^{125}$ I-labelled fibrinogen (obtained from the Radiochemical Centre, Amersham) was injected intravenously into each patient two hours after operation. Scanning with Pitman's localisation monitor 235 was carried out from the first to the 10th day after operation, and any physical signs of DVT were noted. Details of the test and criteria for diagnosis of DVT have been described elsewhere.

Thirty-four patients ( 20 men, 14 women) developed postoperative DVT, giving an incidence of $30 \%(22 \%$ among men; $70 \%$ among women $)$. DVT occurred in only the right leg in 10 , in only the left leg in 18, and in both legs in six patients. DVT was localised to the calf in 30 patients and extended to the lower third of thigh in four. Twenty-four patients $(70 \%)$ developed DVT within 72 hours and four developed it on the fourth, three on the fifth, two on the ninth, and one on the tenth day after operation. Four patients were found to have DVT by physical signs. Ten of the 34 patients who developed DVT were overweight while two were underweight.

\section{Comment}

The impression that postoperative DVT in Africans is rare is widely held largely because clinical methods of detecting DVT have been used. Nevertheless, physical signs are well known to be unreliable, and the ${ }^{125} \mathrm{I}$-labelled fibrinogen technique has been found to be the most sensitive and accurate way of detecting the true incidence of postoperative DVT originating in the calf. ${ }^{3}$

The results of studies in African series have been conflicting: Hassan $e t \mathrm{al}^{4}$ found an incidence of DVT of $9.6 \%$ in Sudanese patients while Joffe ${ }^{5}$ found an incidence of $50 \%$ in the South African Bantu.

Postoperative apnoea has many causes, including the continued effect of the premedicant, the anaesthetic, and neuromuscular blocking

drugs, although these would not seem to be implicated in this case.

\section{Case report}

A 57-year-old normotensive woman with a recent history of transient dysarthria and left-sided weakness was shown by angiography to have bilaterally narrowed internal carotid arteries and vertebral arteries free of disease. She was scheduled for carotid endarterectomy. After premedication with papaveretum $(10 \mathrm{mg})$ and atropine $(0.6 \mathrm{mg})$, anaesthesia was induced with thiopentone $(400 \mathrm{mg})$ and maintained with nitrous oxide, oxygen, and halothane. The trachea was intubated after suxamethonium $(50 \mathrm{mg})$ administration, and ventilation was controlled with the aid of pancuronium $(6 \mathrm{mg})$. After heparinisation (15000 IU) a right carotid endarterectomy was performed. The carotid artery was clamped for 50 minutes and the blood pressure maintained at $140 / 80 \mathrm{~mm} \mathrm{Hg}$. Postoperative recovery was uneventful without neurological sequelae.

One week later an identical procedure was performed on the left side. Anaesthetic details were identical except that the patient was allowed to breathe spontaneously. Eighteen minutes after carotid clamping the patient developed Cheyne-Stokes respiration, and ventilation was assisted for the remainder of the period of clamping ( 20 minutes). Thereafter the respiratory pattern was clinically normal until transfer to the recovery area 50 minutes later. The patient was extubated fully conscious, but five minutes later became apnoeic and cyanosed. The trachea was reintubated and the patient ventilated with oxygen. Naloxone $(0.4 \mathrm{mg})$ was given intravenously, but although still conscious she remained apnoeic. We noted that she would breathe spontaneously when the suction cap on the endotracheal tube was in place and the reservoir bag on the Waters canister full, but became apnoeic immediately after the cap was removed. Verbal or physical stimulation, or replacing the suction cap to distend the reservoir bag, would restore spontaneous ventilation.

After transfer to a respiratory intensive care unit exactly the same picture was confirmed. She was noted to be apnoeic for up to 45 seconds before discretion dictated some stimulus to respiration-a simple quiet command was adequate. For six hours she remained in this state but thereafter was able to breathe adequately. When reviewed two months later she showed no abnormal neurological features.

\section{Comment}


Patients who have undergone bilateral carotid endarterectomy may be insensitive to hypoxia due to carotid body trauma with resulting increased sensitivity to narcotics and barbiturates. ${ }^{2}$ This patient, however, did not respond to naloxone and subsequently received opiates with no untoward effect.

In a procedure such as carotid endarterectomy the effects of changes in cerebral perfusion must also be considered. Most patients tolerate unilateral carotid clamping, but individual variability in the circle of Willis might cause problems. The method of ventilation also affects cerebral perfusion. Hypercapnia, which is likely during spontaneous ventilation, increases total cerebral blood flow but may produce cerebral steal syndromes which decrease flow to areas where perfusion is critical. ${ }^{3}$ We suggest that the combination of these factors may have been responsible for this patient's problem, the resultant hypoperfusion during carotid clamping producing a degree of mid-brain oedema with resultant respiratory depression. At present there is no clear opinion ${ }^{4}$ on the choice between spontaneous and artificial ventilation, but the experience of this case may favour the latter since the first procedure was uneventful.

An unusual feature was the return of spontaneous ventilation with the suction cap in place. Possibly the slight positive pressure generated by the full reservoir bag against the opening resistance of the Heidbrink valve stimulated reflex respiratory activity, the picture seen being akin to Head's paradoxical reflex. ${ }^{5}$

We thank Dr H W C Griffiths and Mr M G Walker for permission to report details of this case.

${ }^{1}$ Fields, W S, et al, fournal of the American Medical Association, 1970, 211, 1993.

2 Wade, J G, et al, New England fournal of Medicine, 1970, 282, 823.

${ }^{3}$ Boysen, G, et al, Anesthesiology, 1971, 35, 286.

${ }^{4}$ Fitch, W, British fournal of Anaesthesia, 1976, 48, 791

${ }^{5}$ Fenn, W O, and Rahn, H, Handbook of Physiology, Section 3, Respiration.

Washington, DC, American Physiological Society, 1964.

(Accepted 3 October 1978)

Department of Anaesthetics, Royal Infirmary, Edinburgh EH3 9YW

DAVID BEAMISH, MB, FFARCS, senior registrar

J A W WILDSMITH, MB, FFARCS, consultant by the left kidney, but an aortogram showed normal renal vessels, and a gammacamera renogram was normal.

Treatment and progress-Oral hydrallazine and propranolol caused postural hypotension, without effect on recumbent blood pressure or the symptoms of headache, anorexia, misery, and pain in the arms. Thirteen days after admission the blood pressure rose to $190 / 150 \mathrm{~mm} \mathrm{Hg}$, and he suffered severe headache. Intravenous diazoxide, $150 \mathrm{mg}$ with $300 \mathrm{mg}$ after three hours, lowered the blood pressure to $160 / 110 \mathrm{~mm} \mathrm{Hg}$; it was thereafter controlled with propranolol $80 \mathrm{mg}$ and hydrallazine $37.5 \mathrm{mg}$ (both three times a day), being $125 / 90 \mathrm{~mm} \mathrm{Hg}$ on discharge 39 days after admission. Twelve weeks after the onset of chickenpox his weight, mood, and personality had recovered. His shoulder girdle muscles, however, wer wasted, with winging of the scapulae and a right wrist drop (see figure). All muscles innervated by cervical roots 5-8 on the right and 5-7 on the left were weak. Tendon reflexes in the arms were reduced. Sensation was normal. Reduced conduction velocity of the right radial nerve was shown five month after the onset of chickenpox. Electromyography suggested partial denervation of the affected muscles.

The antihypertensive drugs were gradually withdrawn 14 to 17 weeks after the onset of chickenpox. One year later the blood pressure remained at $120 / 80 \mathrm{~mm} \mathrm{Hg}$ lying down; it was difficult to assess when he was standing because of indeterminate Korotkoff sounds and narrow pulse pressure. Muscle power continued to improve, with normal everyday function bu residual weakness.

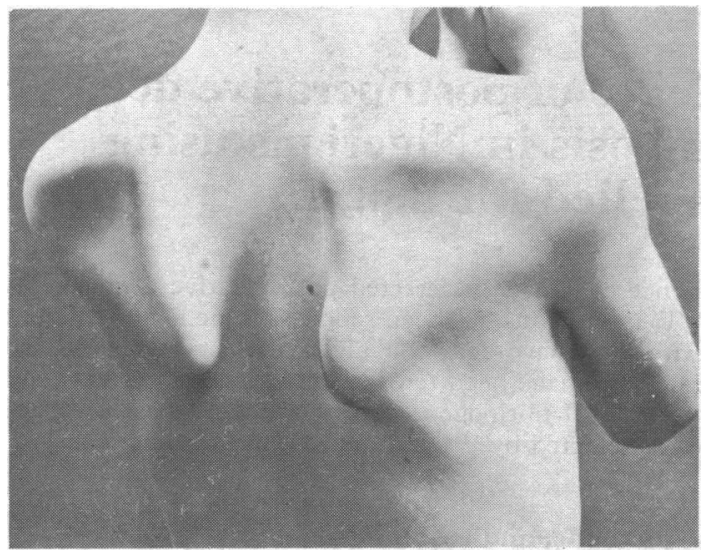

Winging of scapulae.

\section{Transient severe hypertension and polyradiculitis after chickenpox}

Chickenpox can cause encephalitis, cerebellar ataxia, myelitis, polyradiculitis, ${ }^{1-3}$ and glomerulonephritis, ${ }^{45}$ but transient postvaricella hypertension with neurological, but no renal, complications has not been reported. We describe such a case.

\section{Case report}

A healthy 12-year-old boy was recovering from chickenpox when, two weeks after onset, he suffered pain, tenderness, and weakness in the right upper arm and later in the left. Next day he developed headache, vomiting, misery, and weakness; these symptoms worsened until he was admitted to hospital, three weeks after the onset of chickenpox. On admission he was orientated but drowsy and irritable, with weight loss, chickenpox scabs, a pulse rate of 96 beats $/ \mathrm{min}$, an oral temperature of $37.2^{\circ} \mathrm{C}$, blood pressure varying between $140 / 110 \mathrm{~mm} \mathrm{Hg}$ and $165 / 140 \mathrm{~mm} \mathrm{Hg}$, normal volume femoral pulses, normal optic fundi, and an apex beat of normal position and impulse. The right upper arm was tender. Movement of both elbows was weak and flexion and extension of the hips slightly weak. All tendon reflexes were reduced, the ankle jerks and plantar responses being absent.

Investigations-Repeated urine analysis showed occasional slight proteinuria but no erythrocytes, leucocytes, or organisms. The following investigations and values showed no abnormality: urine culture; full blood count and erythrocyte sedimentation rate; serum electrolytes, urea, and creatinine concentrations; serum protein electrophoresis; immunoglobulins, $\mathrm{C} 3$, C4, activated $\mathrm{C} 3$, and total haemolytic complement; $\mathrm{C} 3$ split products antinuclear factor; LE cells; sheep cell agglutination test; anti-DNA antibodies; cerebrospinal fluid pressure, cells, protein, and glucose; urinary catecholamines; chest radiography; electrocardiography; electroencephalography; intravenous phentolamine test; and virus culture of throat swab and cerebrospinal fluid. An intravenous pyelogram showed delayed excretion

\section{Comment}

The severe headache, vomiting, and personality change might indicate encephalitis, but intracranial hypertension causing systemic hypertension was excluded by the absence of papilloedema, raised cerebrospinal fluid pressure, and electroencephalographic changes. No abnormality was found in the renal or immune systems, rendering postvaricella glomerulonephritis unlikely as a cause for the hypertension. The muscle wasting was attributable to postvaricella polyradiculitis of the fifth to eight cervical roots; evidently some other, perhaps autonomic, nervous-system lesion disturbed the control of blood pressure, causing temporary hypertension and persistent postural lability of blood pressure.

We thank Professor I B Houston, Royal Manchester Children's Hospital, for taking over the patient at a critical time and for his helpful criticisms, and Dr M J Noronha, Booth Hall Children's Hospital, Manchester, for carrying out nerve conduction and electromyography studies.

${ }^{1}$ Brain, W, British Medical fournal, 1931, 1, 81.

${ }^{2}$ Bullowa, J G, and Wishik, S M, American fournal of Diseases of Children, 1935, 49, 923.

${ }^{3}$ Miller, H G, Stanton, J B, and Gibbons, J L, Quarterly fournal of Medicine, 1956, 25, 427.

${ }^{4}$ Minkowitz, S, et al, American fournal of Medicine, 1968, 44, 489.

5 Pedersen, F K, and Petersen, E A, Acta Paediatrica Scandinavica, 1975, 64, 886 .

(Accepted 5 October 1978)

Devonshire Road Hospital, Barrow-in-Furness, Cumbria LA14 5NF JOANNE DAVIES, medical student (now house physician, Withington Hospital, Manchester)

R J ROWLATT, MB, MRCP, consultant paediatrician 